\title{
Arte Cemiterial em Pelotas: Uma análise patrimonial e museológica.
}

\author{
Autor : Lucas Moura Barboza- Bacharelando do curso de \\ Museologia-Ufpel - lucas02moura@gmail.com \\ Co-AutorlOrientador: Márcio Dillmann de Carvalho - \\ Doutorando de Memória Social e Patrimônio Cultural \\ marciomdc@yahoo.com.br
}

\section{Resumo:}

As sociedades têm seus diferentes costumes de encarar a morte, suas ações são evidenciadas pelo sentimento de perda e ao vínculo com a perpetuação da memória daquele ente que não está mais em seu convívio. Essa memória é retratada pela construção de monumentos que representam entre vários aspectos, a religiosidade e o poder. Os túmulos e jazigos são os representantes da Arte Cemiterial, esses repletos de informações visíveis e invisíveis, são grandes ferramentas e fontes de memória e história. Suas formas são repletas de símbolos, atributos e alegorias, conjuntos artísticos que correspondem a um importante patrimônio cultural. Na maioria das vezes, tais monumentos não são corretamente evidenciados e protegidos, pretende-se assim neste trabalho analisar sua importância e caracteriza-la através de um viés museológico, relacionado às suas possibilidades de apropriação e mediação. Utilizaremos para este trabalho obras encontrados no Cemitério da Santa Casa, atualmente designado como Cemitério Ecumênico São Francisco de Paula, localizado no bairro Fragata, na cidade de Pelotas, Rio Grande do Sul e fundado em 1856. O ambiente é repleto de imagens e representações escultóricas, atribuídas a importantes artistas plásticos, evidencia-se assim um espetáculo ao céu aberto importante de ser preservado.

Palavras-Chave: Arte cemiterial, Patrimônio, Museologia. 


\section{Introdução}

Em 1790 nascia em Borgonha na França, fruto de uma família nobre, Alphonse Marie Louis de Prat de Lamartine. Alphonse é lembrado como poeta que influenciou o Romantismo francês, um escritor que além de poemas adentrava nos temas mais diferentes e variados através da história, conversas literárias, críticas até mesmo confidências pessoais, também é lembrado por ser um politico idealista, que apoiava o pacifismo e a democracia.

Mas porque trazer aqui Alphonse? Alphonse era interessado pela cultura do oriente, tanto que em vida realizou várias viagens, e de uma em questão, elaborou o livro A Pilgrimage to Holy Land ${ }^{1}$ (Uma Peregrinação a Terra Santa.), obra dividida em três volumes e editada em 1835. E no desenvolvimento dessa obra literária, quando descrevia sua viajem a Grécia, Alphonse escreve “..Esse museu! Eu não visitei! Estou cansado de Museus; eles são cemitérios da Arte!..." . Independente do contesto, onde aparentemente Alphonse parece demonstrar seu incômodo pela exposição e de "fragmentos\mármores" de "destinos $\backslash$ lugares" que ali colocados não tem mais vida, sua frase torna-se celebre e permite várias releituras.

A frase de Alphonse atualmente poderia ser utilizada, conduzindo quem sabe, para as críticas mais veladas que uma instituição museal poderia receber, veicula-la a morte ou descreve-la apenas sem vida, já seria o suficiente para deixar qualquer profissional da área preocupado, mas não é esse o interesse e sim pensar na possibilidade de perceber o cemitério, ambiente vinculado a morte, que ele pode ser um local de contemplação, como um museu.

Atualmente vê-se constatada em determinados lugares a importância e a valorização do Patrimônio encontrado em cemitérios, locais que anteriormente somente se relacionavam a saudade e lembrança daqueles que morreram, para um local de visitação e turismo, lincado a mediação da informação.

\footnotetext{
1 A Pilgrimage to Holy Land-Comprising Recollections, Sketches, and Reflections, Made During a tour in the East. 1832-1833 Pag. 78. I volume. 1835.
} 
Por outro lado, diferentemente dessa valorização pontual, nota-se no Brasil um processo elevado de desinteresse, falta de conservação e preservação e a ocorrência sistemática da depredação e destruição das obras que compõem cemitérios.

\section{Cemitérios, Patrimônio e Museu.}

Quando falamos em cemitérios, naturalmente surge uma grande quantidade de emoções e paradigmas enraizados no cognitivo latente e nas relações sentimentais. $\mathrm{O}$ cemitério é um local de descontinuidade, perda e fim, por outro lado é um ambiente de lembranças e memórias.

Em conjunto com essas relações, ambienta-se a ideia cada vez maior onde o cemitério é foco de trabalhos acadêmicos e sua importância vincula-se atualmente a caracterização dele como patrimônio, sejam pelas suas obras tumulares, esculturas, mausoléus, representações artísticas e históricas, ou simplesmente pelos ilustres moradores que ali habitam.

As politicas e porque não dizer conceituações na forma de lei sobre o patrimônio, tiveram como primeiro aporte o decreto lei de 30 de novembro de $1937^{2}$, onde trazia esta definição legal:

Art. $1^{\circ}$ Constitui o patrimônio histórico e artístico nacional o conjunto dos bens móveis e imóveis existentes no país e cuja conservação seja de interesse público, quer por sua vinculação a fatos memoráveis da história do Brasil, quer por seu excepcional valor arqueológico ou etnográfico, bibliográfico ou artístico. (BRASIL, 1937, p. 1)

$\mathrm{Na}$ atualidade esse conceito tornou-se pequeno para grande quantidade de novos elementos linchados ao patrimônio, mas em todos os casos notamos que o processo de patrimonialização é a construção através de uma legitimação simbólica fornecida pela seleção de determinados itens e bens escolhidos por uma fonte de autoridade. (PRATS, 1998, p.64)

E no contexto dos atos e das ações em busca da preservação do Patrimônio cultural, um dos princípios fundamentais, segundo Oliveira é o "reconhecimento do valor intrínseco dos conhecimentos tradicionais associados à biodiversidade e à

\footnotetext{
${ }^{2}$ Decreto lei no 25/1937 - Organiza a proteção do patrimônio histórico e artístico nacional.
} 
diversidade Cultural". (OLIVEIRA, 2004, p.4) Demonstra-se assim que a sociedade elege seus patrimônios, definindo quais o são, sempre ligados a valores e ao reconhecimento.

Como podemos ver relações entre o museu e o cemitério? O cemitério advêm do

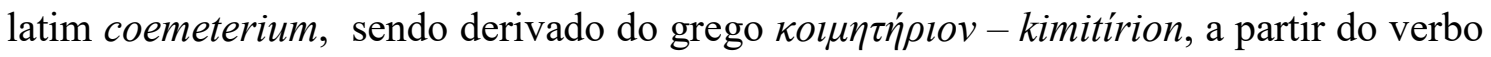

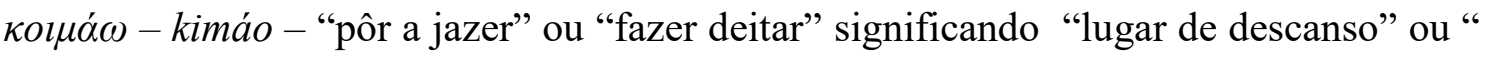
lugar de dormir" . (CARNEIRO, 2012, p.32) Por outro lado temos os museus, que se originam do grego : mouseion : o templo das musas, seu termo designa a instituição ou lugar onde se exibem e guardam coleções de itens, objetos, obras de arte representantes da cultura, ciência e história.

Por definição temos nos estatutos do Conselho Internacional de Museus (ICOM):

O museu é uma instituição permanente, sem fins lucrativos, a serviço da sociedade e do seu desenvolvimento, aberta ao público, que adquire, conserva, estuda, expõe e transmite o patrimônio material e imaterial da humanidade e do seu meio, com fins de estudo, educação e deleite. (ICOM, 2007)

Acredita-se que é na vertente do ato da representação e da exposição que encontramos os vínculos do cemitério e do museu. Em um cemitério, as obras reproduzidas em túmulos ou mausoléus, adornos e objetos de decoração, que interpretam a vida e a morte, e quase sempre estão são ligados as qualidades e virtudes daquele ali sepultado, essas são chamados de Arte tumular ou funerária.

Os cemitérios são locais de imenso significado simbólico e palco de informações e fontes, é o que sugere O Professor Harry Bellono, que lista algumas importantes contribuições, entre elas Fontes Histórica para a preservação da memória familiar e coletiva; Fonte de estudos e crenças; Forma de expressão do gosto artístico; Forma de expressão da ideologia política; Forma de preservação do patrimônio histórico; Fonte para conhecer a formação étnica; Fonte para o estudo da genealogia; Fonte reveladora da perspectiva de vida. (BELLOMO, 2000. p.15)

Por mais que seja perceptível, a sociedade expressa neste local seu sentimento de morte, do profano e do sagrado, da mesma forma ali observamos a busca pela 
conservação da memória e da identidade. Preservar a memória do local, sua arte e sua história é características e missão de um museu.

\section{Cemitérios São Francisco de Paula: Sugestão através da mediação museológica.}

$\mathrm{Na}$ história do município de Pelotas, observamos os aspectos naturalmente usados pelos antigos, conforme o falecimento ocorria, o enterro era em pleno campo, distante das habitações. Conforme Gutierrez, existiram vários cemitérios de menor porte na cidade, sendo que em 1825 foram transferidos para local onde atualmente é a Avenida Bento Gonçalves, local que era suficiente para a cidade.

Mas com o advento da cólera-morbo, que já havia aportado ao Rio de Janeiro e não demorou para chegar ao município, fez-se a necessidade de construção de um grande número de catacumbas,. Em nove de novembro 1855, já tínhamos o primeiro cadáver colérico e em apenas mais dez dias já haviam mais de 30, a partir desse momento começou a se utilizar o Cemitério da Santa Casa, no Fragata, atualmente denominado Cemitério São Francisco de Paula.(GUTIERREZ, 1994, p. 53)

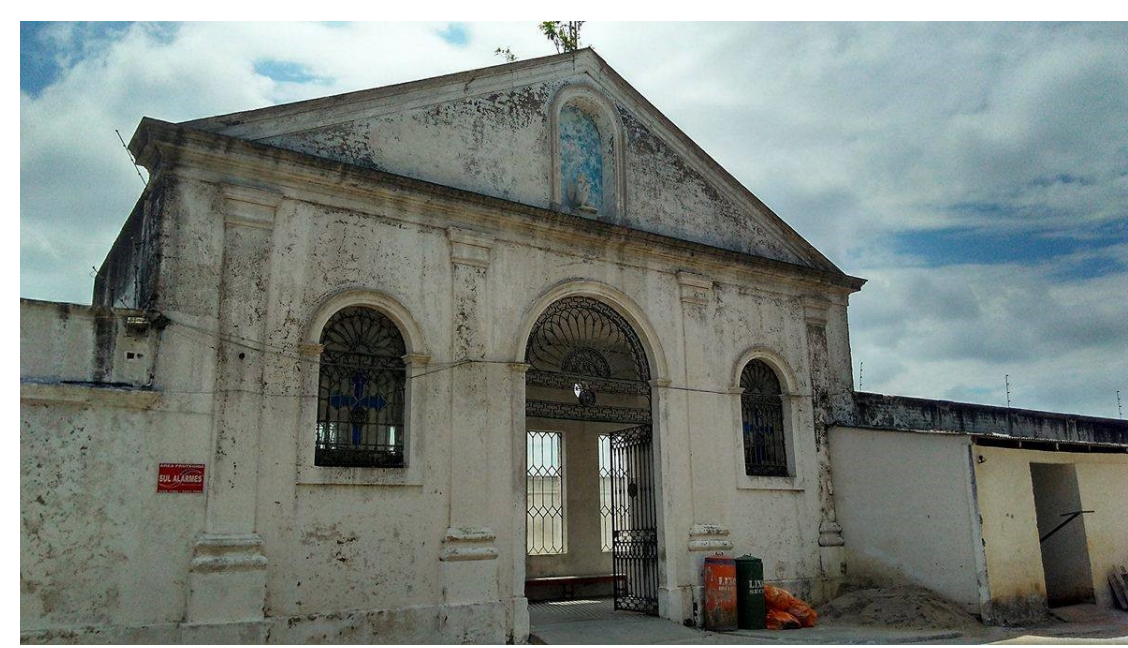

Imagem 1: Entrada do Cemitério Antigo Fonte: Márcio D. Carvalho.

O cemitério São Francisco de Paula tem em sua ala mais antiga uma grande variedade de túmulos e mausoléus, que remontam os tempos de grande bonança e influência que a cidade teve perante o Estado Rio Grande do Sul e o Brasil. Para uma 
cidade que ficou conhecida como a "Princesa do Sul", temos além dos seus resquícios de história, representadas pelas as charqueadas ou suntuosos prédios centrais, a herança artística e cultural que pode ser vista em na última morada dos seus ilustres ou desconhecidos cidadãos.

Para compreender, provocar o interesse e demonstrar a importância deste patrimônio pelotense, podemos utilizar a prática museológica, sua visão e a maneira de significar ou resinificar os itens que fazem parte do acervo do cemitério, aqui no caso, seus túmulos ou mausoléus.

A ação de interagir levando a informação e provocando o conhecimento é o principal combustível da museologia, vai da pesquisa à sensibilidade da exposição, poderíamos tecer vários adjetivos para esse processo até mesmo denominações, mas aqui provocamos de maneira sugestiva a palavra mediação.

No contexto da disciplina e o estudo da museologia, verificamos o uso da mediação, podendo citar a obra Chaves da Museologia de Desvalles e Mairesse que descreve a mediação:

Ao falarmos de mediação na museologia, vem rapidamente a cabeça o termo mediar, A mediação designa a ação de reconciliar ou colocar em acordo duas ou várias partes, isto é, no quadro museológico, o público do museu com aquilo que lhe é dado a ver. (DESVALLÉES, MAIRESSE 2013 p.52)

$\mathrm{O}$ ato de mediar para a museologia em geral está muito mais próximo do trabalho realizado pelo profissional que assessora o processo de contato do visitante com as exposições ou peças do acervo. Muitas vezes os museus utilizam o mediador como ferramenta de informação adicional, além daqueles colocadas em etiquetas ou placas explicativas.

Mas podemos buscar em outras áreas conceituações para esse ato, a mediação para autores da Ciência da Informação tem significado pouco diferente, a definição de Almeida Júnior e Bortolin para a mediação é:

É toda ação de interferência - realizada pelo profissional da informação -, direta ou indireta; consciente ou inconsciente; singular ou plural; individual ou coletiva; que propicia a apropriação de 
informação que satisfaça, plena ou parcialmente, uma necessidade informacional. (ALMEIDA JUNIOR, BORTOLIN, 2008. P.74)

Se utilizarmos essa ideia, podemos dizer que todo o ato de processo e elaboração de uma exposição, em seus menores detalhes é um ato de mediação de informação, sendo assim o museólogo exercendo seu trabalho é um mediador. E por isso sugerimos ainda de maneira provocativa uma ação de mediação possível no Cemitério São Francisco de Paula em Pelotas.

Uma das maneiras que sugestionaremos é o processo de mediação dos itens representativos nos cemitérios, para isso poderíamos usar o trabalho da pesquisa histórica, o aprofundamento das informações extrínsecas e intrínsecas, que potencializam a significação dos itens visitados, o seu entorno, assim como a sua leitura iconográfica.

A iconografia tem origem dos termos gregos eikon-ícone e grafia-escrita, a "escrita da imagem", é a ciência que estuda os sistemas e os questionamentos a respeito do conteúdo e significado das obras de arte. A iconografia é o estudo descritivo das representações visuais encontradas nos símbolos e imagens.

Iconografia é o ramo da história da arte que trata do tema ou mensagem das obras de arte em contraposição à sua forma. Tentemos, portanto, definir a distinção entre tema ou significado, de um lado, e forma, de outro. (PANOVISKY, 1986, p.47)

A iconografia é mais uma ferramenta para enriquecer de informações o visitante, a ideia de musealizar objetos de um espaço onde o público frequentador naturalmente vai por outro motivo, emerge uma característica cultural e social não convencional ainda no Brasil, gerando um estranhamento. Sobre o local, Foucault ${ }^{3}$ descreve os cemitérios como ambientes ou locais de heterotopia. Foucault usa o termo para caracterizar os espaços que são formados por múltiplas camadas de relações e significados com outros lugares, e que não pode ser visto facilmente devido a sua complexidade.

\footnotetext{
${ }^{3}$ FOUCAULT. De outros espaços. 2013.
} 
$\mathrm{O}$ autor descreve a existência de locais restritos, que funcionam em condições adversas, não-hegemônicas, podendo conectar períodos de tempos diversos, são locais concebidos por regras de comportamento, os próprios museus são considerados heterotopias temporais, segundo Foucoult o cemitério é uma heterotopia que ao longo do tempo a sociedade modificou, ele lembra dos cemitérios que inicialmente situavamse junto a Igreja, foram depois deslocados para locais distantes e periféricos, da integração com a cidade e sociedade para distancia e a percepção de outro local, como a cidade dos mortos. (FOUCAULT, 2013 p.117)

Como exemplo de trabalho escolhemos o mausoléu da Família Gonçalves Chaves, tendo como tronco Antônio José Gonçalves Chaves, português nascido na Vila Verde do Ouro na Comarca de Chaves. Antônio veio para o Brasil muito cedo e se estabeleceu no então Povo de São Francisco de Paula, foi inicialmente caixeiro, chegando a estancieiro, vereador e charqueador, proprietário da Charqueada São João.

Descrito pelo botânico francês Auguste Saint-Hilare em seu livro Viagem ao Rio Grande do Sul como um homem culto e rígido com seus escravos, Gonçalves Chaves também fui autor do livro Memórias Ecônomo-politicas sobre a administração publica no Brasil. O charqueador foi morar no Uruguai com o início da Revolução Farroupilha, tendo uma propriedade no Cerro, em Montevidéu. Em 29 de julho de 1837, o barco que o levava para a Charqueada naufragou provocando sua morte. (GUTIERREZ, 1994)

O mausoléu inicia-se em forma de antiguidade com o Dr. Antônio José Gonçalves Chaves Filho (Pelotas, 1813 + Rio de Janeiro, 1871), filho de Antônio José Gonçalves Chaves e Maria do Carmo Secco, foi político, vice-cônsul do Brasil em Montevideo, deputado provincial por três legislaturas, além disso, cursou a Faculdade de Direito em São Paulo. Seu nome está envolto em destaque, pois se encontra a frente do mausoléu, acompanhado de uma coroa de flores. 


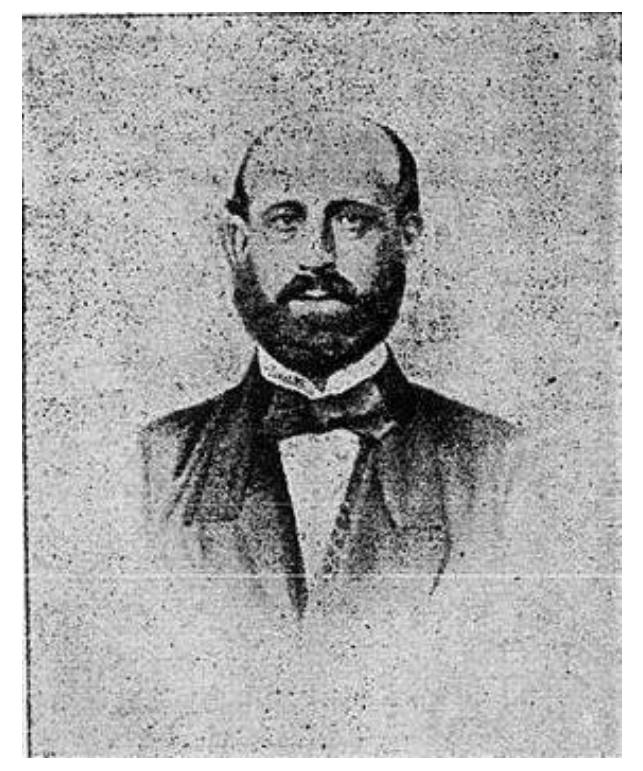

Imagem 2: Dr. José Gonçalves Chaves Filho

Fonte: Almanak Litterário e Estatístico do Rio Grande do Sul.-1898.

Encontra-se também seus filhos, o Dr. Álvaro José Gonçalves Chaves, que era um jovem advogado, fundador do partido republicano rio-grandense, propagandista dos ideais da abolição da escravatura. (3 setembro de $1861+22$ fevereiro de 1890). No seu epitáfio vê-se gravado : " No vigor da mocidade prostrado pela morte, so poude dar ao mundo os prelúdios de uma vida ilustre. Mas, pelo que fez, revelou o que faria. Alma angélica para quem a pureza era uma necessidade alma que unia a energia a bondade. teve a menos a gloria de ver realizado o seu sonho de patriota, viu a liberdade dos escravos e expirou saudando o sol nascente da republica." Demonstrada aqui de certa forma sua "visão diferenciada" a seu avô, e pai, ambos charqueadores e escravistas. 




Imagem 3: Dr. José Gonçalves Chaves Filho

Fonte: Almanak Litterário e Estatístico do Rio Grande do Sul.-1898

O Dr. Bruno Chaves (6 julho 1864+ 10 abril de 1923) foi ministro do Brasil no Império da Áustria, logo depois ser ministro junto a Santa Sé -Vaticano, sendo recebido em audiência pelo Papa Pio X, seu epitáfio tem a seguinte descrição: " Medico $e$ diplomata, apostolo do bem da verdade e da justiça, varão de excelsas virtudes cívicas e chistãns, no amor á família a Pátria e á Humanidade “.

O terceiro irmão é o Dr. José Gonçalves Chaves (9 abril $1866+28$ outubro 1907), formou-se em engenharia no Rio de Janeiro, fez parte da Sociedade Abolicionista Sul Rio-Grandense, do Clube Republicano Rio-Grandense, foi engenheiro da estrada de ferro Southern, deputado estadual, presidente da Sociedade Agrícola Pastoril do Rio Grande do Sul, diretor da Sociedade Minas de Cobre de Camaquã, presidente da Associação Comercial e diretor da Companhia Rio-Grandense de Iluminação e gás. 


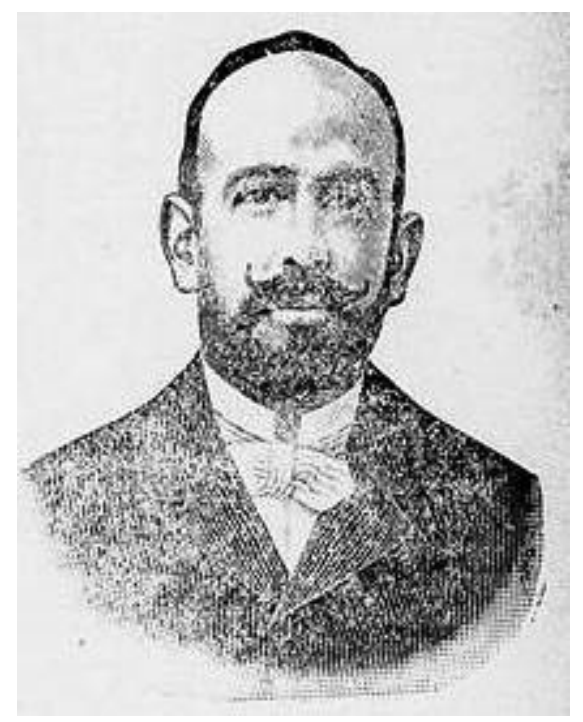

Imagem 4: Dr. José Gonçalves Chaves

Fonte: Almanak Litterário e Estatístico do Rio Grande do Sul.-1898

Com menores informações temos Guido Gonçalves Chaves, que em 1910 foi membro da Sociedade Brasileira para a Animação da Agricultura e proprietário de sesmarias em Capão do Leão e o filho do Dr. Bruno Chaves, Antônio José Gonçalves Chaves (31 maio $1901+18$ outubro 1958) este último representado com alegorias colocadas em sua lápide caracterizando-o como maçom.

Podemos trabalhar os significados e traduções instituídas pelos símbolos dispostos no mausoléu, sabendo de uma maneira clara que a significação simbólica é particularmente extensa e diversificada. Inicialmente surge uma característica muito comum, a forma da estrutura clássica, como um templo, sua representação está ligada ao sagrado, ao recinto perfeito e harmónico. Contornado por colunas que simbolizam a união entre o céu e a terra, também representa a firmeza e a força. (Becker, 2007) 


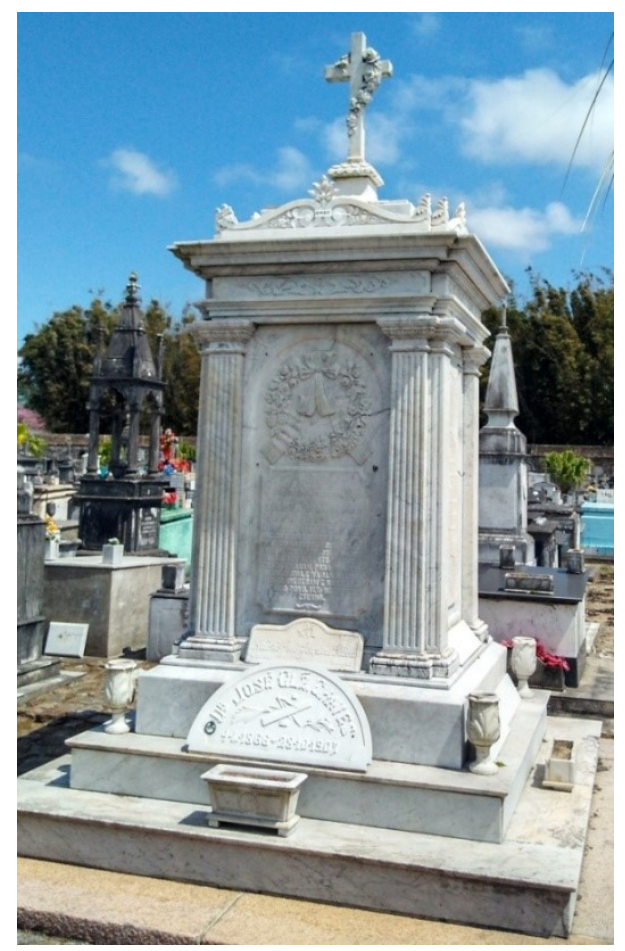

Imagem 5: Mausoléu Gonçalves Chaves Fonte: Márcio D. Carvalho.



Imagem 6: Ampulheta e asa

Fonte: Márcio D. Carvalho.

Aqui verificamos um símbolo composto, a ampulheta e a asa. A ampulheta é um símbolo da passagem do tempo e da morte, com o escoamento da areia finaliza-se um período, também pode ser relacionada como símbolo do fim e do recomeço ao ser virado, pode relacionar-se com ciclos e épocas e entre as quatro virtudes cardeais a ampulheta simboliza a temperança. (BECKER, 2007, p. 20) 
A asa tem seus significados ligados aos pássaros, ao voo, a chegada ao céu, o espirito que deixa o corpo e claro o próprio tempo. (BECKER, 2007, p.210)

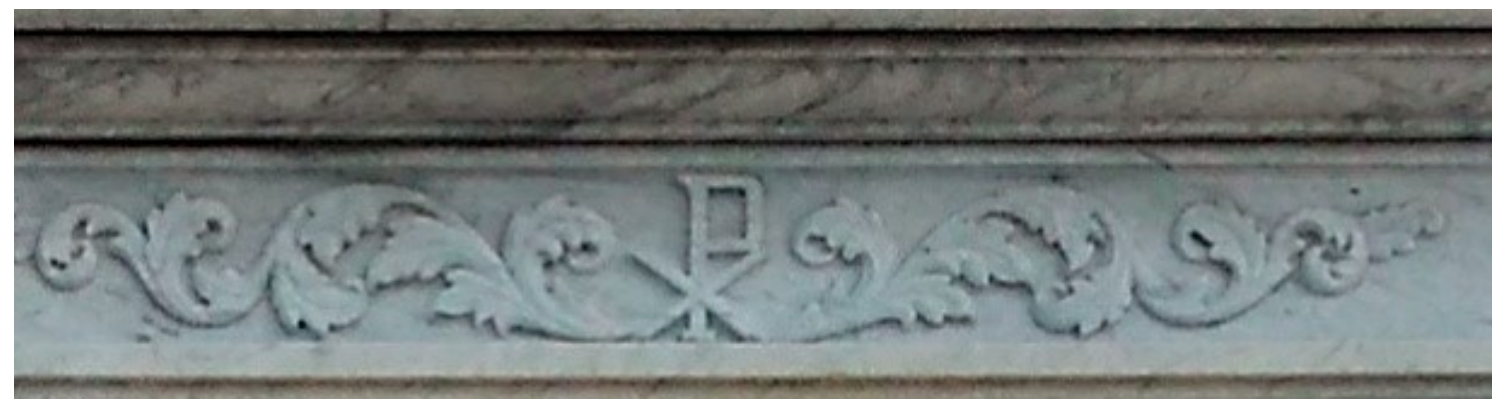

Imagem 7: Monograma XP

Fonte: Márcio D. Carvalho.

Aqui vemos a representação do monograma CHI (X) e RHO (P) da palavra grega XPICTOC (monograma de Cristo). Também é chamado de Chismon, anteriormente poderia ver representado pelas letras $\mathrm{J}$ e $\mathrm{X}$, com um circulo é o símbolo cósmico e solar, pode ser encontrado com as letras A e W (Alfa e Ômega- inicio e fim), ou também o sol e a lua. (BECKER, 2007, p. 191)



Imagem 8: Flores- Glicídios Fonte: Márcio D. Carvalho. 
Comumente são usadas flores para ornar os túmulos, algumas são de fácil caracterização, palmas, rosas, lírios, ramos de oliveira, trigo, mas no caso do mausoléu dos Gonçalves Chaves, na face que elenca o Dr. Bruno Gonçalves Chaves, identificamos o que parece ser uma glicínia. A planta em questão tem algumas características simbólicas, no budismo esta relacionada ao brilho e transitoriedade da vida, também em outras culturas é chamada a "flor da ternura", ainda mais que seu nome vem do grego " glykos" que significa doce.

As flores são símbolos da beleza, da humanidade e por sua perenidade também é relacionada a instabilidade e transitoriedade, suas cores tem relações, flores amarelassol; flores brancas - morte ou inocência; flores vermelhas - sangue e flores azuis com o sonho e mistério .( BECKER, 2007, p.132)

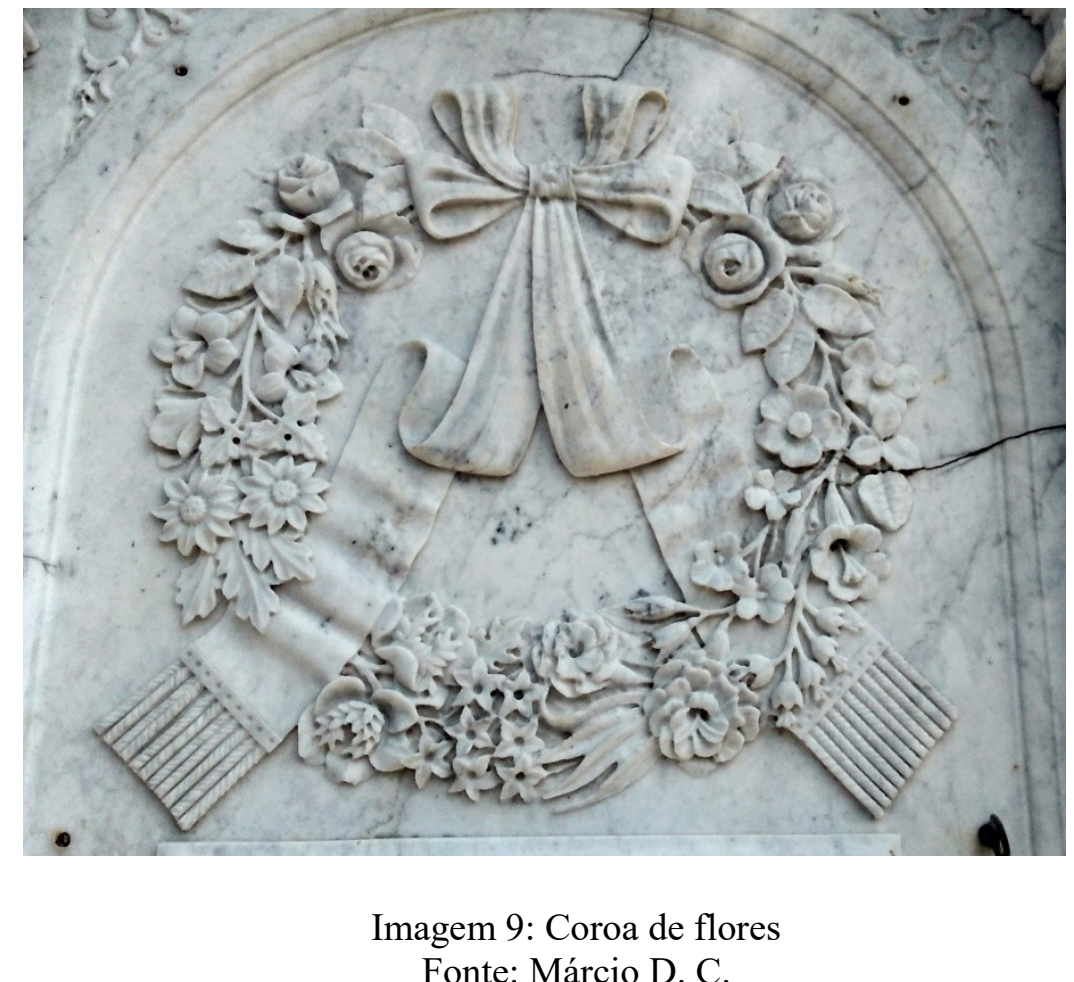

Coroa de flores na antiguidade era a representação da distinção de pessoas consagradas ou divindades, no cristianismo era sinal de salvação alcançada, muito encontrada em túmulos com outros símbolos como monograma de cristo, a pomba e o cordeiro. (BECKER, 2007, p. 74) 


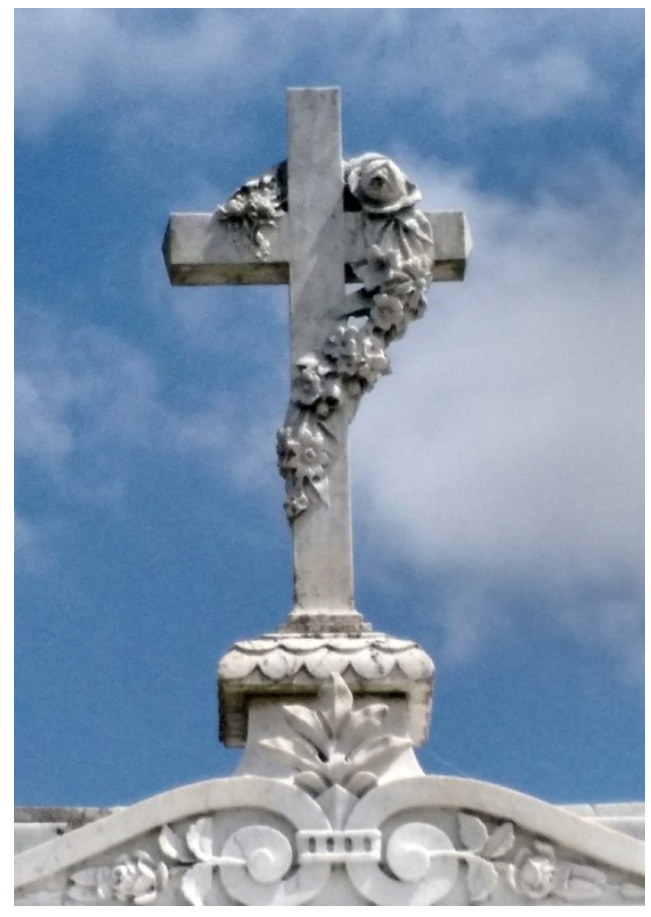

Imagem 10: Cruz .

Fonte: Lucas Barboza.

A cruz é um símbolo que poderemos encontrar significados em vários locais, era descrita como os pontos cardeais, foi associada ao numero quatro, sinal de encruzilhada ou os dois eixos significando equilíbrio. É um dos símbolos mais antigos do cristianismo, pela morte de Cristo na cruz, é símbolo de seu sofrimento, mas também de triunfo. Dependendo das flores utilizadas em conjunto podem ter outros significados, por exemplo, o uso de lírios na cruz simboliza a Páscoa e representam a ressureição. (BECKER, 2007)


Imagem 11: Esquadro compasso e régua.

Fonte: Lucas Barboza. 
O compasso é um instrumento representativo, ele está relacionado à inteligência que planeja e projeta, é símbolo de força, trabalho ponderado, prudência, moderação, verdade e justiça, já o esquadro simboliza a terra, retidão, franqueza e legitimidade, por sua vez a régua razão e caráter. (BECKER, 2007) Estes mesmos instrumentos interligados representam a arquitetura e a engenharia, logo a maçonaria ${ }^{4}$, também estão diretamente ligados ao trabalho, onde busca-se ser justo e perfeito. (PUSCH, 1982, p.103)

A morte é constantemente simbolizada nos túmulos, lápides e mausoléus, pode ser uma corrente rompida, uma âncora quebrada, uma tocha invertida e para a maçonaria ela é simbolizada como uma coluna quebrada. (CARVALHO, CHAVES, 2015 p. 7)

Essas e outras informações são propostas que podem ser ampliadas e melhoradas, sendo fundamental pensar no cemitério como local de patrimônio, informação e cultura, concepção visualizada no cemitério da Consolação ${ }^{5}$, que fez um projeto criando guias de visitação, mapas que auxiliam o visitante, dividindo túmulos em intelectuais, artistas e homens públicos, políticos e escultures, transformando assim o espaço e lançando perspectivas para as possibilidades de visitação, informação, pesquisa e conhecimento.

\footnotetext{
${ }^{4}$ A maçonaria é uma sociedade iniciática de homens ditos livres e de bons costumes que tem cunho universal, fraternal, progressista, filosófico, filantrópico, místico e libertário. (PUSCH. 1982, p.120)

${ }^{5}$ Cemitério da Consolação foi fundado em 10 de julho de 1858 , sendo o primeiro cemitério público, e o mais antigo em funcionamento na cidade de São Paulo. Localiza-se no distrito da Consolação, na região central da capital paulista.
} 


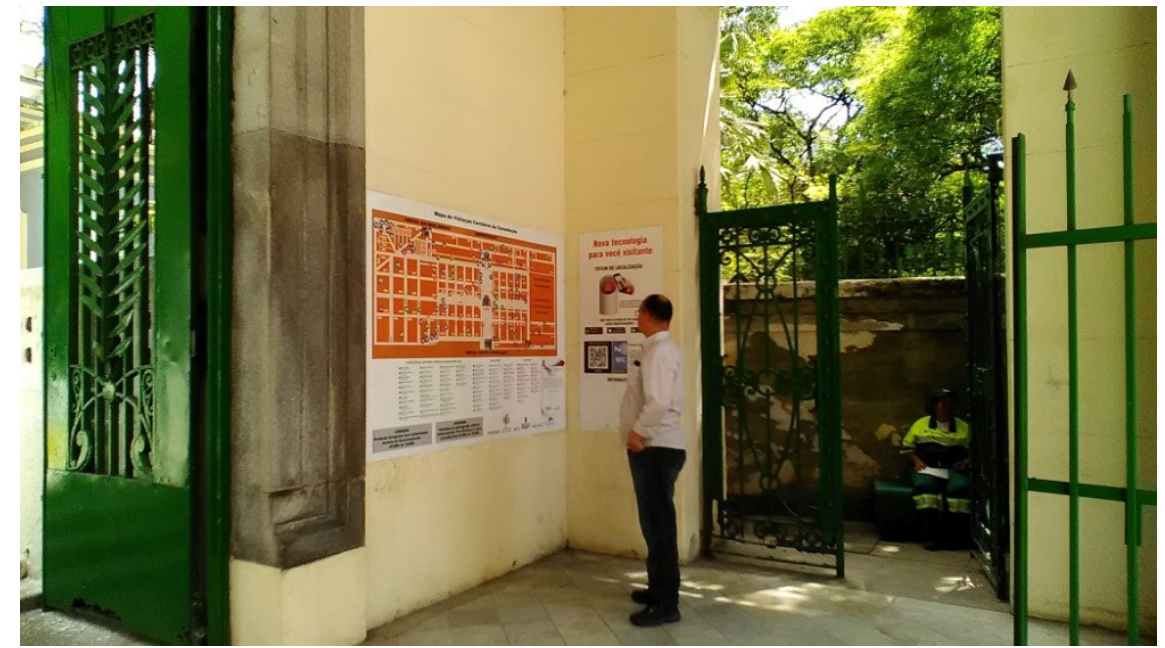

Imagem 12: Mapas para visitação-Cemitério da Consolação-SP . Fonte: Andrea Messias.

Fora realizado também para os visitantes folders que contam a história do museu, além de propor uma interação do visitante com as novas tecnologias, onde através de um aplicativo de celular, pode-se obter informações adicionais através da leitura de um QR code colocado próximo da obra.

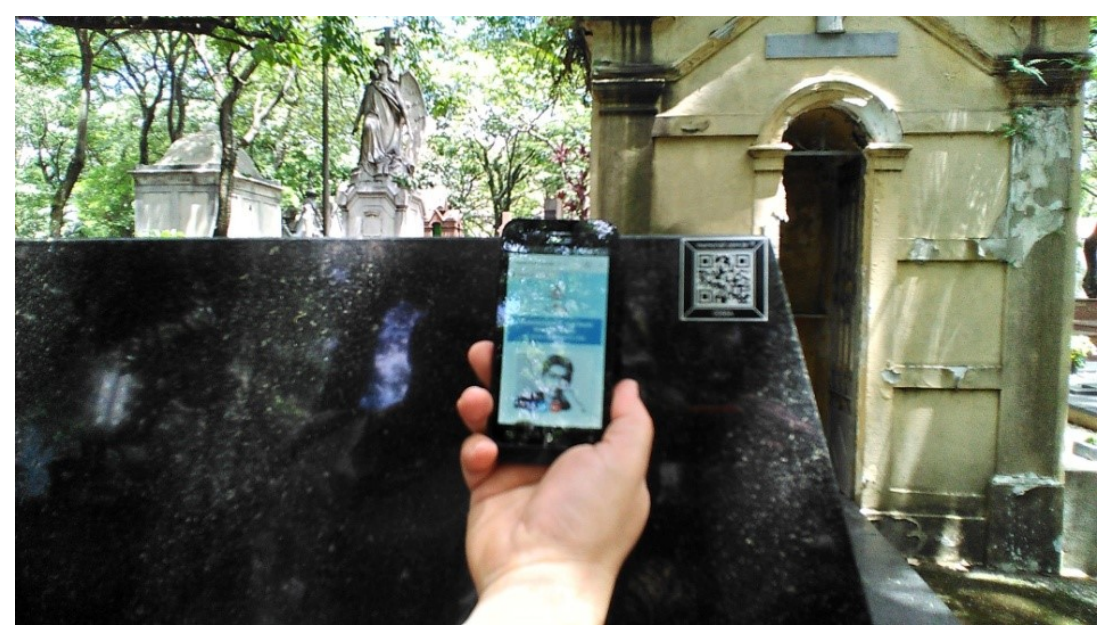

Imagem 13: Mapas para visitação-Cemitério da Consolação-SP.

Fonte: Andrea Messias. 


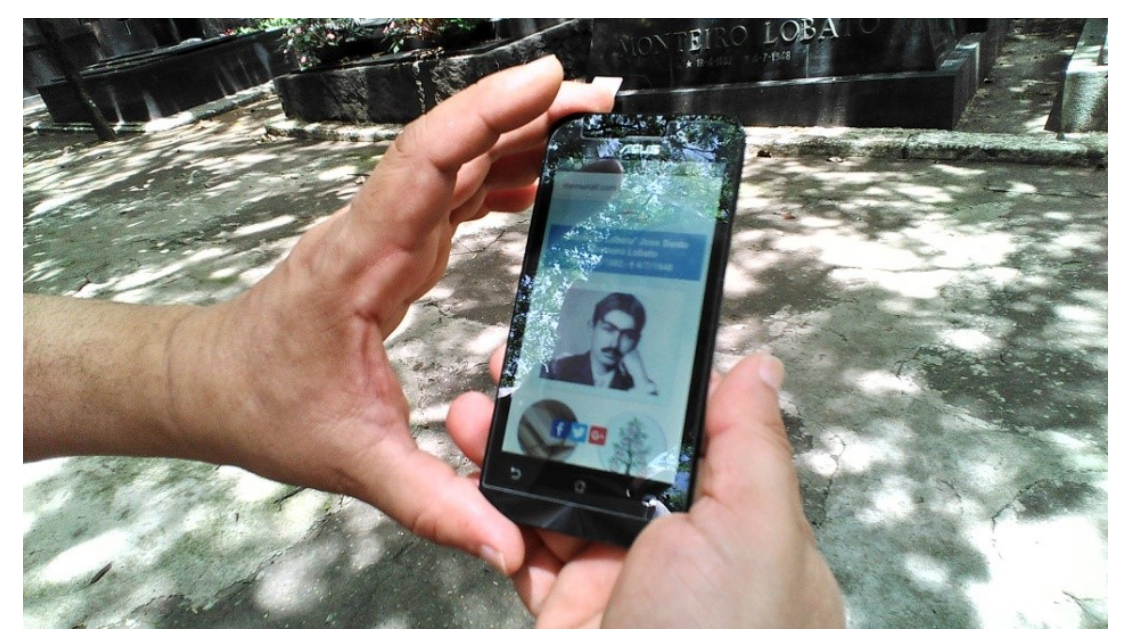

Imagem 14: Tumulo Monteiro Lobato-Cemitério da Consolação-SP.

Fonte: Andrea.

O Brasil ainda encontra-se muito atrasado no que se diz respeito a preservação deste patrimônio, infelizmente o Cemitério São Francisco de Paula é local de depredação e vandalismo, por isso demonstra-se a importância de mostrar exemplos que tentam melhorar a perspectiva de valorização do local, acredita-se que se rapidamente não existir uma intervenção que viabilize a salvaguarda dos itens lá existentes, logo aos únicas imagens que teremos das obras serão as fotografias.

\section{Referencial bibliográfico}

ALMEIDA JÚNIOR, Oswaldo Francisco de; BORTOLIN, Sueli. Mediação da informação e da leitura. In: SILVA, Terezinha Elisabeth da (Org). Interdisciplinaridade e transversalidade em Ciência da Informação. Recife: Néctar, v.1 2008, p.67-86.

Almanak Litterario e Estatístico do Rio Grande do Sul para 1898. Organizado por Alfredo Ferreira Rodrigues. Decimo Anno. Rio Grande.

Andrea Cunha Messias - Fotografias tiradas no Cemitério da Consolação. São Paulo 2016.

BELLOMO, Harry Rodrigues (Org.).Cemitérios do Rio Grande do Sul: arte, sociedade, ideologia. Porto Alegre: EDIPUCRS,2000.

BECKER, Udo. Dicionário de Símbolos. Editora Paulos. $2^{\circ}$ Edição, São Paulo, 1999. 
BORGES, Maria Elízia; SANTANA, Marissol M.; BIANCO, Sabrina Del. Arte funerária no Brasil: possibilidades de interagir nos programas de ensino, de pesquisa e de extensão na universidade. In: ENCONTRO NACIONAL DA ANPAP, 13., 2004, Brasília. [Anais eletrônicos...]. Brasília: Universidade de Brasília, 2004. p. 192-200.

BORGES, Maria Elizia. Arte funerária no Brasil: uma pesquisa peculiar no campo das artes visuais. Locus - Revista de História- UFJF. Edição Atual, edição 37/2014. ISSN 1413-3024.

BRASIL .Decreto -lei $n^{\circ} 25$, de 30 de novembro de 1937 . Organiza a proteção do patrimônio histórico e artístico nacional. Disponível em: < http://www.planalto.gov.br/ccivil_03/Decreto-Lei/Del0025.htm>. Acessado em: 13 de fevevereiro de 2017.

CARNEIRO, Maristela. Construção tumulares e representações de alteridade : materialidade e simbolismo no cemitério Municipal de São José, Ponta Grossa/PR, 1881-2011. Ponta Grossa: Universidade Estadual de Ponta Grossa, 2012 (Dissertação de Mestrado)

CARVALHO, Márcio Dillmann de. CHAVES, Larissa Patron. Estudo sobre simbologia maçônica nas logotipias de documentos do Museu Maçônico Rocco Felippe. In: XIV Seminário de História da Arte. Volume V. Pelotas. Ufpel. 2015.

DESVAlLÉES A., \& MAIRESSE, F. Conceitos-chave de museologia. Comitê Internacional para Museologia do ICOM; Comité Nacional Português do ICOM. Florianópolis: $\quad$ FCC, $2014 . \quad$ Disponível em: $<$ http://icom.museum/fileadmin/user_upload/pdf/Key_Concepts_of Museology/Conceito s-ChavedeMuseologia pt.pdf $>$ Acessado em 15 de janeiro de 2017.

DESVALLÉES, André; MAIRESSE, François. Conceitos-chave de Museologia. Tradução: Bruno Brulon Soares, Marília Xavier Cury. ICOM: São Paulo, 2013.

FOUCOULT, Michael. De outros espaços. In: Estudos Avançados. USP- Universidade Federal de São Paulo. V.27, n.79. 2013.

FOUCAULT, Michel. "Outros espaços", in: Ditos e escritos III - Estética: Literatura e pintura, música e cinema. Rio de Janeiro: Forense Universitária, 2003, p. 415.

GUITEIRREZ, Ester. Pelotas Século XIX - Cadernos e folhas de arquitetura e urbanismo. Editora Universitária- Ufpel. Pelotas . 1994.

LAMARTINE, Alphonse . A Pilgrimage to Holy Land-Comprising Recollections, Sketches, and Reflections, Made During a tour in the East. 1832-1833 . New York I vol. 1835 .

OLIVEIRA, Ana Gita de. Salvaguarda do Patrimônio Cultural : Bases para Constituição de Direitos. Revista do IPHAN. Outubro-2004. Disponível em :http://iphan.gov.br Acessado $1 \mathrm{~m} 28$ de janeiro de 2017. 
PANOFSKY, E. "Iconografia e Iconologia: Uma Introdução ao estudo da arte da Renascença" . In: Significado nas Artes Visuais . Tradução: Maria Clara F. Kneese e J. Guinsburg.São Paulo : Perspectiva, 2ª ed., 1986 , p. 47.

PRATS, Llorenç. El concepto de patrimônio cultural.Política y Sociedad,n.27,p.63-76, 1998.

PUSCH, Jaime. ABC do aprendiz. Edição do autor. $2^{\circ}$ Edição, Tubarão. SC. 1982. 